\title{
COVID-19 and SARS Coronavirus 2: Antibodies for the Immediate Rescue and Recovery Phase
}

\author{
Scott B. Halstead ${ }^{1 *}$ and Ramesh Akkina ${ }^{2 *}$ \\ ${ }^{1}$ Independent Researcher, Bethesda, MD, United States, ${ }^{2}$ Department of Microbiology, Immunology and Pathology, \\ Colorado State University, Fort Collins, CO, United States
}

Keywords: antibody protection for Covid-19, SARS-CoV-2 immunity, gamma globulin for Covid-19 protection, antibody therapy for Covid-19, convalescent plasma for Covid-19 therapy, vaccine and therapeutics testing for Covid-19, human volunteer testing for Covid-19 protection, SARS Coronavirus 2 and Covid-19 immunity

\section{OPEN ACCESS}

Edited by:

Urszula Krzych,

Walter Reed Army Institute of

Research, United States

Reviewed by:

Raffael Nachbagauer,

Icahn School of Medicine at Mount

Sinai, United States

${ }^{*}$ Correspondence:

Scott B. Halstead

halsteads@erols.com

Ramesh Akkina

akkina@colostate.edu

Specialty section:

This article was submitted to

Vaccines and Molecular Therapeutics,

a section of the journal

Frontiers in Immunology

Received: 24 April 2020

Accepted: 13 May 2020

Published: 29 May 2020

Citation:

Halstead SB and Akkina R (2020) COVID-19 and SARS Coronavirus 2: Antibodies for the Immediate Rescue and Recovery Phase.

Front. Immunol. 11:1196.

doi: 10.3389/fimmu.2020.01196
The world is in the grip of a devastating SARS-CoV-2 pandemic causing a major health havoc and economic hardship/slowdown. In most affected countries mitigation of transmission by quarantining and social distancing is beginning to reduce hospitalization rates. However, current estimates are that the pandemic will continue for many months. What can be done immediately to control the damage and manage a transition to normalcy?

One approach is to reduce disease severity. A near-term possibility is to treat high risk patients with repurposed existing drugs (1). Another is to use antivirals such as remdesivir, a nucleotide analog, which has been previously shown to have efficacy against MERS disease in a monkey model $(2,3)$ and now under clinical investigation in China, USA and elsewhere. Recent preliminary results showed some efficacy and more in-depth studies are still underway (3). New compounds will undoubtedly emerge from the laboratory. Antibodies offer promising treatment options. Convalescent SARS antibodies administered early in acute illness were shown to reduce disease severity (4). Efforts are well-underway to manufacture therapeutic gamma globulin from COVID-19 convalescent sera, or alternatively to derive neutralizing monoclonal antibodies $(5,6)$.

A second approach is to protect high risk persons such as the elderly and persons with preexisting conditions that include high blood pressure, diabetes, and obesity. Antibodies can be used to protect the vulnerable from infection. After WW II commercial gamma globulin was widely available affording short term protection against measles, paralytic poliomyelitis, hepatitis $\mathrm{A}$, and hepatitis B (7-11). In the 1950s, a large scale blinded efficacy trial found that gamma globulin given to 100,000 children successfully blunted poliomyelitis attack rates (9). To prevent SARSCoV-2 infections, gamma globulin antibody preparations or monoclonal antibodies can be given to those at high risk of fatal outcome. This requires use of another tool-epidemiology. Careful studies in populations suffering high infection rates should be able to identify risk factors for severe and fatal disease. Protective gamma globulin, once on the market, can be made available to self-identified high-risk persons through family health care providers. Persons in at high risk commercial occupations, health care workers and care givers should be protected. Commercial tests for detecting SARS-CoV-2 IgG antibodies are now on the market. Antibody testing can identify those who are immune and those who at risk and eligible for immunoprotection.

Progress is being made in developing neutralizing monoclonal human antibodies while at the same time the population of COVID-19 convalescents is growing rapidly. These antibodies should be put to work to help manage the pandemic. This will require that immune products be shown to prevent SARS-CoV-2 infections in human volunteers (12). SARS-CoV-2 has been adapted to grow in Vero cells (13). While there is risk, COVID-19 in young adults is seldom a severe disease. There is a long history of using a human challenge model to establish candidate therapeutic and preventive products for microbial pathogens (14-16). Such an approach should help shorten 
the typical long time it takes for vaccine/therapeutic testing. Once a protective level of antibody in humans can be correlated with an in vitro value it should be possible to screen candidate products more swiftly. The degree of protection may not confer complete sterilizing immunity but should impede viral spread to pulmonary stage and progression to severe disease. To avoid possible antibody-dependent enhancement (ADE) of COVID19 infections, the Fc terminus of $\operatorname{IgG}$ antibodies should be removed or inactivated. However, this should be studied further to determine whether the risk of $\mathrm{ADE}$ outweighs the potential benefits afforded by antibody-dependent cellular cytotoxicity (ADCC) or antibody-dependent cellular phagocytosis (ADCP) $(17,18)$. Strategic exploitation of antibody-based approaches can help us return to normalcy. Indeed, as an example, using

\section{REFERENCES}

1. Gao J, Tian Z, Yang X. Breakthrough: chloroquine phosphate has shown apparent efficacy in treatment of COVID-19 associated pneumonia in clinical studies. Biosci Trends. (2020) 14:72-3. doi: 10.5582/bst.2020.01047

2. de Wit E, Feldmann F, Cronin J, Jordan R, Okumura A, Thomas T, et al. Prophylactic and therapeutic remdesivir (GS-5734) treatment in the rhesus macaque model of MERS-CoV infection. Proc Natl Acad Sci USA. (2020) 117:6771-6. doi: 10.1073/pnas.1922083117

3. Mahase E. Covid-19: Remdesivir is helpful but not a wonder drug, say researchers. BMJ. (2020) 369:m1798. doi: 10.1136/bmj.m1798

4. Mair-Jenkins J, Saavedra-Campos M, Baillie JK, Cleary P, Khaw FM, Lim WS, et al. The effectiveness of convalescent plasma and hyperimmune immunoglobulin for the treatment of severe acute respiratory infections of viral etiology: a systematic review and exploratory meta-analysis. J Infect Dis. (2015) 211:80-90. doi: 10.1093/infdis/jiu396

5. Shanmugaraj B, Siriwattananon K, Wangkanont K, Phoolcharoen W. Perspectives on monoclonal antibody therapy as potential therapeutic intervention for Coronavirus disease-19 (COVID-19). Asian Pac J Allergy Immunol. (2020) 38:10-8. doi: 10.12932/AP-200220-0773

6. Casadevall, Pirofski L. The convalescent sera option for containing COVID19. J Clin Invest. (2020) 130:1545-8. doi: 10.1172/JCI138003

7. Young MK, Nimmo GR, Cripps AW, Jones MA. Post-exposure passive immunisation for preventing measles. Cochrane Database Syst Rev. (2014) 1:Cd010056. doi: 10.1002/14651858.CD010056.pub2

8. Janeway CA. Use of concentrated human serum gamma-globulin in the prevention and attenuation of measles. Bull N Y Acad Med. (1945) 21:202-22.

9. Rinaldo CR Jr. Passive immunization against poliomyelitis: the Hammon gamma globulin field trials, 1951-1953. Am J Public Health. (2005) 95:7909. doi: 10.2105/AJPH.2004.040790

10. Krugman S, Ward R. Infectious hepatitis: current status of prevention with gamma globulin. Yale J Biol Med. (1961) 34:329-39.

11. Smetana HF, Smetana FG. Viral hepatitis in United States soldiers stationed in Korea, 1967-1970: prophylactic efficacy of gamma globulin. Bull N Y Acad Med. (1976) 52:535-60. widespread serological testing, Germany is issuing "immunity certificates" to those who can safely re-enter the normal work force.

\section{AUTHOR CONTRIBUTIONS}

All authors listed have made a substantial, direct and intellectual contribution to the work, and approved it for publication.

\section{FUNDING}

Work done in the RA laboratory is supported by NIH Grants RO1 AI120021 and RO1 AI123234.

12. Eyal N, Lipsitch M, Smith PG. Human challenge studies to accelerate coronavirus vaccine licensure. J Infect Dis. (2020) 221:1752-6. doi: 10.1093/infdis/jiaa152

13. Harcourt J, Tamin A, Lu X, Kamili S, Sakthivel SK, Murray J, et al. Severe acute respiratory syndrome coronavirus 2 from patient with (2019). novel coronavirus disease, United States. Emerg Infect Dis. (2020) 26:126673. doi: 10.3201/eid2606.200516

14. Sabin AB, Schlesinger RW. Production of immunity to dengue with virus modified by propagation in mice. Science. (1945) 101:640-2. doi: 10.1126/science.101.2634.640

15. Kirkpatrick BD, Whitehead SS, Pierce KK, Tibery CM, Grier PL, Hynes NA, et al. The live attenuated dengue vaccine TV003 elicits complete protection against dengue in a human challenge model. Sci Transl Med. (2016) 8:330ra36. doi: 10.1126/scitranslmed.aaf1517

16. Matuschewski K, Borrmann S. Controlled Human Malaria Infection (CHMI) Studies: Over 100 Years of Experience with Parasite Injections. Methods Mol Biol. (2019) 2013:91-101. doi: 10.1007/978-1-4939-9550-9_7

17. Wan Y, Shang J, Sun S, Tai W, Chen J, Geng Q, et al. Molecular mechanism for antibody-dependent enhancement of coronavirus entry. J Virol. (2020) 94:e2015-19. doi: 10.1128/JVI.02015-19

18. Halstead SB, Mahalingam S, Marovich MA, Ubol S, Mosser DM. Intrinsic antibody-dependent enhancement of microbial infection in macrophages: disease regulation by immune complexes. Lancet Infect Dis. (2010) 10:71222. doi: 10.1016/S1473-3099(10)70166-3

Conflict of Interest: The authors declare that the research was conducted in the absence of any commercial or financial relationships that could be construed as a potential conflict of interest.

Copyright (C) 2020 Halstead and Akkina. This is an open-access article distributed under the terms of the Creative Commons Attribution License (CC BY). The use, distribution or reproduction in other forums is permitted, provided the original author(s) and the copyright owner(s) are credited and that the original publication in this journal is cited, in accordance with accepted academic practice. No use, distribution or reproduction is permitted which does not comply with these terms. 